\title{
Spatial eco-risk assessment and prediction of heavy metal pollution in surface soil: a preliminary assessment of an urban area from a developing country
}

\begin{abstract}
This study was conducted to investigate the total concentrations of heavy metals (Al, Cd, Co, $\mathrm{Cr}, \mathrm{Cu}, \mathrm{Fe}, \mathrm{Pb}$, and $\mathrm{Zn}$ ), evaluate potential ecological risks, and predict the heavy metal contamination of surface soil in Klang District (Malaysia). Iron ( Fe) was discovered as the highest while Cadmium (Cd) was the lowest heavy metal concentration in the surface soil of Klang district. Based on the data collected, the mean values for potential ecological risk index of single elements decreased from cadmium to chromium. Predicted fixed numbers of years were 11 and 21 for $\mathrm{Cd}$ accumulations at accelerated and uniform modes, respectively.
\end{abstract}

Keyword : Heavy metal; Surface soil; Ecological risk; Prediction; Pollution 